\title{
Montelukast reduces airway eosinophilic inflammation in asthma: a randomized, controlled trial
}

\author{
E. Pizzichini*, J.A. Leff ${ }^{+}$, T.F. Reiss ${ }^{+}$, L. Hendeles ${ }^{\#}$, L-P. Boulet ${ }^{\ddagger}$, L.X. Wei ${ }^{+}$, \\ A.E. Efthimiadis*, J. Zhang ${ }^{+}$, F.E. Hargreave*
}

Montelukast reduces airway eosinophilic inflammation in asthma: a randomized, controlled trial. E. Pizzichini, J.A. Leff, T.F. Reiss, L. Hendeles, L-P. Boulet, L.X. Wei, A. Efthimiadis, J. Zhang, F.E. Hargreave. (C) ERS Journals Ltd 1999.

ABSTRACT: Leukotrienes are pro-inflammatory mediators which may contribute to tissue, sputum, and blood eosinophilia seen in allergic and inflammatory diseases, including asthma. Montelukast is a cysteinyl leukotriene ${ }_{1}\left(C_{y s} \mathbf{L T}_{1}\right)$ receptor antagonist which improves asthma control; the aim of this study was to investigate its effect on induced sputum eosinophils.

Montelukast $10 \mathrm{mg}(\mathrm{n}=19)$ or placebo $(n=21)$ were administered orally once in the evening for 4 weeks to 40 chronic adult asthmatic patients, aged 19-64 yrs, in a double-blind, randomized, parallel group study. Patients were included if, at prestudy, they had $>5 \%$ sputum eosinophils, symptomatic asthma with a forced expiratory volume in one second $\geq 65 \%$ of the predicted value and were being treated only with "as needed" inhaled $\beta_{2}$-agonists. In addition to sputum eosinophils, blood eosinophils and clinical endpoints were also assessed.

Four weeks of montelukast treatment decreased sputum eosinophils from $7.5 \%$ to $3.9 \%$ (3.6\% decrease, $95 \%$ confidence interval (CI) -16.6-0.4). In contrast, placebo treatment was associated with an increase in sputum eosinophils from $14.5 \%$ to $17.9 \%$ (3.4\% increase, 95\% CI -3.5-9.8). The least squares mean difference between groups $(-11.3 \%, 95 \%$ CI $-21.1--1.4)$ was significant $(p=0.026)$. Compared with placebo, montelukast significantly reduced blood eosinophils $(p=0.009)$, asthma symptoms $(p=0.001)$ and $\beta_{2}$-agonist use $(p<0.001)$ while significantly increasing morning peak expiratory flow $(p=0.001)$. Montelukast was generally well tolerated in this study, with a safety profile similar to the placebo.

These results demonstrate that montelukast decreases airway eosinophilic inflammation in addition to improving clinical parameters. Its efficacy in the treatment of chronic asthma may be due, in part, to the effect on airway inflammation. Eur Respir J 1999; 14: 12-18.
*Asthma Research Group, St. Joseph's Hospital-McMaster University, Hamilton, Ontario, Canada. 'Depts of Pulmonary/ Immunology and Biostatistics, Merck Research Laboratories, Rahway, NJ, USA. \#University of Florida Health Sciences Center, Gainesville, FL, USA. Unite de Recherche en Pneumologie, Hospital Laval, Saint-Foy, Quebec, Canada.

Correspondence: T.F. Reiss Merck Research Laboratories P.O. Box 2000

Rahway, NJ 07065

USA

Fax: 17325947830

Keywords: Airway inflammation asthma

cysteinyl leukotriene receptor antagonists montelukast

sputum eosinophils

Received: July 281998

Accepted after revision March 21999

This study was supported by a grant from Merck Research Laboratories, Rahway, NJ, USA.
Asthma is associated with increased eosinophils in the airways, lung tissue and peripheral blood, which can correlate with asthma severity [1]. Airway eosinophilia has been observed in chronic stable asthma, after allergen inhalation and during exacerbations [2-5]. When activated by various stimuli, eosinophils cause inflammation by releasing toxic products including oxygen radicals, basic proteins, cytokines and cysteinyl leukotrienes (CysLTs) [6]. Bronchial inflammation is considered to be a cause of symptoms and airflow limitation in asthma.

CysLTs are chemoattractants for eosinophils in vitro [7]. In guinea-pigs, leukotriene $(\mathrm{LT}) \mathrm{D}_{4}$ causes eosinophil influx into the bronchoalveolar lavage (BAL), lung tissue, and conjunctiva, all of which are inhibited by (LT) receptor antagonists $[8,9]$. In humans, inhalation of $\mathrm{LTE}_{4}$ and $\mathrm{D}_{4}$ increase bronchial tissue and sputum eosinophils [10, 11]. Inhibition of LT synthesis decreases airway eosinophils in asthmatic patients [12] and blunts the increase in BAL eosinophils after segmental allergen challenge in allergic patients [13].

Montelukast is a potent, specific, oral cysteinyl leukotriene $_{1}\left(\mathrm{CysLT}_{1}\right)$ receptor antagonist which improves the signs and symptoms of asthma [14-18]. Montelukast treatment also significantly decreases blood eosinophils [15].

Recently, induced sputum has been introduced as a reliable, valid, and responsive method to safely obtain airway secretions [19]. In contrast to BAL and bronchial biopsy, induced sputum has the additional advantage of being noninvasive, thus allowing repeated measurements during treatment [3, 4, 19-23].

In this study, induced sputum eosinophils were measured to investigate the effect of 4 weeks of daily treatment with montelukast on airways inflammation. In this randomized, placebo-controlled, double-blind trial, the effect of treatment on blood eosinophils and clinical outcomes were also evaluated.

Patients and methods

\section{Patients}

Symptomatic adult asthma patients capable of producing induced sputum at a prestudy visit, with a proportion of eosinophils $>5 \%$, were consecutively enrolled in the study 
(table 1). The diagnosis of asthma was established by symptoms of asthma and by an improvement in the prebronchodilator forced expiratory volume in one second $(\mathrm{FEV} 1) \geq 15 \%$ after salbutamol $(200 \mu \mathrm{g})$. The asthma was mild as indicated by an FEV1 between 60 and $85 \%$ of predicted. All patients had a minimum level of daytime symptoms (weekly score of at least 32 out of a possible 168 ), and required inhaled $\beta_{2}$-agonists on an as-needed basis (weekly average, 1 puff.day ${ }^{-1}$ ) as recorded on a daily diary card completed during the week before allocation. The asthma was stable; there had been no exacerbations or need for any other treatment for one month, and no hospitalizations for asthma occurred within 3 months of the prestudy visit. Specifically, no patient had previously used an antileukotriene drug. Patients were otherwise healthy, were nonsmokers for at least $1 \mathrm{yr}$ (with a smoking history of no more than 10 pack-yrs), consumed their usual diet and maintained their usual exercise regimen. None had an unresolved sinus or upper respiratory tract infection within 3 weeks before the prestudy visit. Females of childbearing potential had a negative test result for serum $\beta$-human chorionic gonadotropin $(\beta-h C G)$ at the prestudy visit and agreed to use contraception during the study. The Ethical Review Committees and Institutional Review Boards of all participating centres approved the study and all subjects gave written informed consent.

\section{Study design}

This six-centre, randomized, double-blind, placebo-controlled, parallel-group trial was comprised of 6 weekly visits: the first (prestudy visit) for patient selection, the second (baseline visit) for allocation to treatment (after a 1-week baseline period), and the remaining four to collect efficacy and safety data during the treatment period. At the prestudy visit, informed consent was obtained and sputum was induced. Patients were given placebo study medication in a single-blind manner and were instructed to continue their prestudy treatment, to record symptoms, the use of asneeded $\beta_{2}$-agonists, and morning and evening peak expiratory flow (PEF) on a daily diary card. Additionally, patients refrained from inhaled salbutamol and caffeinated beverages for at least $6 \mathrm{~h}$, and any antihistamine medication for at least $48 \mathrm{~h}$, before a study visit, and contacted a study physician if a deterioration in symptoms or PEF occurred. Qualifying patients underwent allergy skin testing and sputum induction, and were allocated randomly according to a

Table 1. - Mean baseline patient characteristics

\begin{tabular}{lcc}
\hline Parameter & Montelukast & Placebo \\
\hline Subjects M/F & $12 / 7$ & $12 / 9$ \\
Age (range) yrs & $31(19-64)$ & $28(19-62)$ \\
Atopic n & 18 & 20 \\
Asthma symptom score & $2.5 \pm 0.83$ & $2.17 \pm 0.70$ \\
$\beta_{2}$-agonist use puffs $\cdot$ day & \\
PEFa.m. L·min & $4.70 \pm 2.9$ & $4.10 \pm 2.8$ \\
FEV1 \% pred & $424 \pm 72.2$ & $429 \pm 81.8$ \\
Sputum eosinophils \% & $69.2 \pm 10.9$ & $68.9 \pm 14.7$ \\
Blood eosinophils $10^{6}$ cells $\cdot \mathrm{mL}^{-1}$ & $6.9 \pm 9.1$ & $14.1 \pm 14.2$ \\
\hline
\end{tabular}

Data are presented as mean \pm SD. M: male; F: female; PEFa.m.: morning peak expiratory flow; FEV1: forced expiratory volume in one second. computer-generated schedule to receive either montelukast $10 \mathrm{mg}$ or matching image placebo tablets once daily at bedtime. Sputum was induced again 1 and 4 weeks after treatment allocation. Clinical efficacy measurements (FEV1, PEF, daytime asthma symptoms) were performed over the 4-week treatment period. Blood safety tests (including eosinophil counts) were performed at prestudy and 2 and 4 weeks after allocation.

\section{Clinical measurements}

Patients recorded the number of as-needed $\beta_{2}$-agonist puffs used, morning and evening PEF (the best of three measures using a Mini-Wright peak flow meter (Clement Clark Inc., Columbus, OH, USA)), and daytime asthma symptom scores on a daily diary card validated for its measurement and linguistic properties [24]. Spirometry was performed according to American Thoracic Society criteria [25] between 06:00 h and 09:00 h, 8-10 h after the previous (bedtime) dose of study drug. For each time point, the best FEV1 value from at least three measurements was used for analysis. Reversibility was determined by administering salbutamol $200 \mu \mathrm{g}$ through a spacer device (Aerochamber ${ }^{\mathrm{TM}}$; Monaghan Medical Corporation, Plattsburgh, NY, USA) and measuring FEV1 10-30 min later. Allergy skin tests were carried out by the skin prick technique with a minimum of five aeroallergen extracts appropriate to the geographical location. A weal diameter at least $3 \mathrm{~mm}$ larger than the diluent control was considered positive.

\section{Sputum and blood examination}

Study site personnel were trained to perform sputum induction and processing in a standardized manner. Sputum was induced as described by PIN et al. [22] with an aerosol of hypertonic saline $(3,4$ and $5 \%)$ generated by a Fisoneb $^{\mathrm{TM}}$ ultrasonic nebulizer (Canadian Medical Products Ltd., Markham, Ontario, Canada). Sputum separated from saliva was processed as described by PIzzichini et al. [19]. Briefly, sputum was treated by adding four volumes of $0.1 \%$ dithiothreitol (DTT), sputalysin $10 \%$ (Calbiochem Corp., San Diego, CA, USA) followed by four volumes of Dulbecco's phosphate-buffered saline (DPBS). The suspension was filtered through a $48-\mu$ m nylon gauze (BBSH Thompson, Scarborough, Ontario, Canada) and total cell counts of leukocytes and cell viability (trypan blue exclusion method) were determined. The cell suspension was adjusted to $1.0 \times 10^{6}$ cells $\cdot \mathrm{mL}^{-1}$ and cytocentrifuge preparations were made using $60 \mu \mathrm{L}$ of the cell suspension (Shandon III cytocentrifuge, Shandon Southern Instruments, Sewickly, PA, USA). Four cytospins were made, air dried, coded and sent to a central laboratory for reading (St. Joseph's Hospital, Hamilton, Ontario, Canada). Two were stained by Wright's stain for a differential cell count on at least 400 nonsquamous cells, and two were fixed in Carnoy's fixative and stained with toluidine blue for a differential cell count on at least 1,500 metachromatic cells (mast cells and basophils). Squamous cells were measured as a percentage of the total cell population; results of the other cells were expressed as a percentage of the total nonsquamous cell count.

Blood was collected in venoject tubes and sent to a central laboratory (Covance Central Laboratory Services 
Table 2. - Sputum cell counts

\begin{tabular}{|c|c|c|c|c|c|}
\hline \multirow{2}{*}{ Cell type } & \multirow{2}{*}{ Treatment } & \multicolumn{2}{|c|}{ Cells } & \multirow{2}{*}{$\begin{array}{c}\text { Difference in } \\
\text { least-squares mean* } \%\end{array}$} & \multirow{2}{*}{$\begin{array}{c}95 \% \mathrm{CI} \\
\text { of difference \% }\end{array}$} \\
\hline & & Baseline & Last visit & & \\
\hline \multirow[t]{2}{*}{ Eosinophil } & Placebo & $14.54 \pm 14.40$ & $17.90 \pm 19.79$ & & \\
\hline & Montelukast & $7.53 \pm 9.52$ & $3.88 \pm 4.67$ & -11.27 & $(-21.11--1.44)^{+}$ \\
\hline \multirow[t]{2}{*}{ Neutrophil } & Placebo & $35.83 \pm 19.45$ & $33.12 \pm 22.88$ & & \\
\hline & Montelukast & $41.47 \pm 28.27$ & $45.85 \pm 29.32$ & 7.23 & $(-7.50-21.96)$ \\
\hline \multirow[t]{2}{*}{ Lymphocyte } & Placebo & $1.80 \pm 1.38$ & $1.68 \pm 1.19$ & & \\
\hline & Montelukast & $1.41 \pm 1.54$ & $1.49 \pm 1.08$ & 0.19 & $(-0.61-0.99)$ \\
\hline \multirow[t]{2}{*}{ Macrophage } & Placebo & $47.19 \pm 17.52$ & $46.96 \pm 21.50$ & & \\
\hline & Montelukast & $49.32 \pm 26.93$ & $48.33 \pm 28.64$ & -1.23 & $(-17.99-10.53)$ \\
\hline \multirow[t]{2}{*}{ Bronchial epithelial cell } & Placebo & $0.43 \pm 0.86$ & $0.35 \pm 0.52$ & & \\
\hline & Montelukast & $0.28 \pm 0.43$ & $0.46 \pm 0.88$ & 0.29 & $(-0.40-0.98)$ \\
\hline \multirow[t]{2}{*}{ Metachromatic cell } & Placebo & $0.11 \pm 0.12$ & $0.11 \pm 0.19$ & & \\
\hline & Montelukast & $0.08 \pm 0.07$ & $0.08 \pm 0.06$ & 0.00 & $(-0.09-0.08)$ \\
\hline
\end{tabular}

Data are presented as mean $\pm \mathrm{SD}$, single value or range. ${ }^{*}$ : analysis of covariance. CI: confidence interval. ${ }^{+}: \mathrm{p}=0.026$.

Inc., Indianapolis, IN, USA), which analysed blood chemistry, haematology and differential (including eosinophil) cell counts.

\section{Slide reading}

All slides were independently evaluated by two readers blinded to treatment, study site and visit. The average value for each cell type was calculated. A previous validation study using the same readers employed in this study demonstrated that the one week concordance correlation coefficient [26] within reader was $>0.98$, while between readers was $>0.99[19]$.

\section{Statistical analysis}

The percentage change in sputum eosinophils from baseline (the allocation visit) to the Week-4 value (primary hypothesis) was analysed using an analysis of covariance (ANCOVA) model including factors for centre, treatment, and baseline. The ANCOVA model was used to adjust differential regression to the mean effects due to the imbalance in baseline values. While sputum eosinophils had to be $>5 \%$ at the prestudy visit, some baseline (allocation visit) values were $<5 \%$. Therefore, a confirmatory analysis was performed on patients with baseline sputum eosinophils $>3 \%$ (considered significantly elevated [27]) to exclude baseline values too low to show meaningful decreases during treatment. Treatment by baseline interaction was also evaluated as was the change from baseline to the Week-1 (first visit after allocation) value using the same model. The average treatment period change from baseline for peripheral blood eosinophils was also compared between treatment groups using this model. Postallocation sputum eosinophil data were excluded from analysis if prespecified criteria confounding efficacy measurements, such as an upper respiratory tract infection, occurred. For clinical endpoints, the average treatment period changes (daytime symptom score, PEF) or average per cent changes (FEV1, $\beta_{2}$-agonist use) were summarized (mean \pm SD) and compared between treatment groups using an analysis of variance (ANOVA) model including factors for treatment and centre. The between treatment differences were summarized as least squares means and $95 \%$ confidence intervals (CI) using the ANOVA model. All available data were used for the analysis of clinical endpoints. A p-value $\leq 0.05$ was considered statistically significant.

The study was designed with a treatment group sample size of $\mathrm{n}=18$ to have $80 \%$ power ( $\mathrm{SD}=65 \%$ (log scale) at an $\alpha=0.05$, two-tailed test) to detect a reduction of $50 \%$ in the change from baseline in the percentage of eosinophils between treatment groups.

\section{Results}

\section{Patient allocation and exclusion from sputum analysis}

Forty eligible patients were randomized to active treatment (19 to montelukast, 21 to placebo). Three patients in the montelukast group did not have Week-4 sputum samples available. Two of these patients were discontinued, one owing to an adverse event (abdominal pain) and one owing to a protocol deviation. Data from one placebo patient were excluded from sputum analysis because an upper respiratory tract infection occurred within 5 days after randomization (prespecified criteria). All allocated patients were included in clinical endpoint and safety analyses.

\section{Effect of montelukast on sputum and blood cell counts}

The characteristics of sputum cells in each group were examined before treatment. Eleven patients in the montelukast group and 17 in the placebo group had sputum eosinophils $>3 \%$ at baseline visit. Compared with montelukast, the proportion of sputum eosinophils at baseline was higher in the placebo group whether including all subjects (table 2) or analysing only patients with sputum eosinophils $>3 \%$ (mean eosinophils of 10.6 and $17.1 \%$ for montelukast and placebo, respectively).

While there was some variability in response, the effects of treatment on sputum eosinophils in most patients within each group were similar. Four weeks of treatment with montelukast significantly reduced the percentage of sputum eosinophils. In contrast, there was an increase in sputum eosinophils after treatment with placebo (table 2, fig. 1). These effects were evident after the first week (decrease of $2.6 \%$ and increase of $2.0 \%$ from baseline for montelukast and placebo, respectively, $\mathrm{p}=0.177$ ) and progressed over the remaining weeks of therapy. The mean $(95 \% \mathrm{CI})$ 


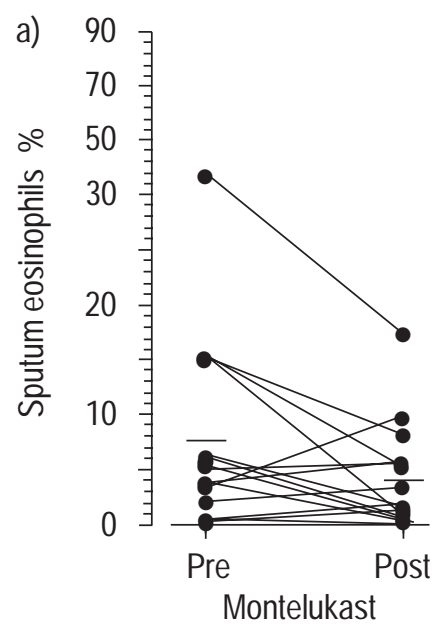

b)

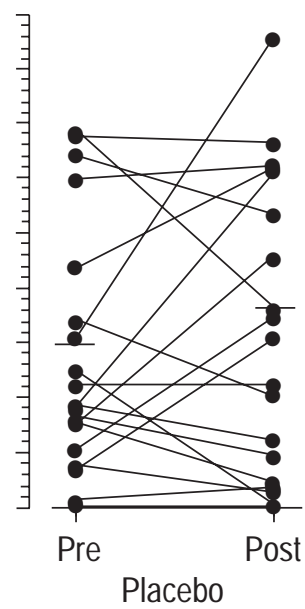

Fig. 1. - The effect of: a) montelukast $(n=16)$; and b) placebo $(n=20)$ on sputum eosinophils at baseline (Pre) and after 4 weeks (Post) of therapy. Each point is the mean from two blinded readers. Horizontal bars represent mean values. The percentage of eosinophils (mean $\pm \mathrm{SD}$ ) decreased from $7.53 \pm 9.52$ to $3.88 \pm 4.67$ in the montelukast group and increased from $14.54 \pm 14.40$ to $17.90 \pm 19.79$ in the placebo group $(\mathrm{p}=0.026)$.

changes in sputum eosinophils were $-3.6 \%(-16.6-0.4)$ and $3.4 \%(-3.5-9.8)$ in the montelukast and the placebo group, respectively. Similar changes were observed in the patients with sputum eosinophils $>3 \%$.

Over the four week treatment, montelukast significantly reduced the number of peripheral blood eosinophils compared with placebo (fig. 2). The mean difference from baseline was -0.09 (decrease of $25 \%$ ) and -0.01 (decrease of $2 \%$ ) in the montelukast and placebo groups, respectively $(\mathrm{p}=0.009)$.

\section{Effect of montelukast on clinical endpoints}

Compared with placebo, montelukast treatment produced a significant reduction (mean $(95 \% \mathrm{CI}))$ in the daytime asthma symptoms -0.7 $(-1.1--0.3)(\mathrm{p}=0.001)$ and $\beta_{2^{-}}$ agonist use $-8.1 \%(-100.4--35.7),(\mathrm{p}<0.001)$, and an increase in morning PEF $39.0(16.8-61.2) \mathrm{L} \cdot \mathrm{min}^{-1}$, $(\mathrm{p}=0.001)$. There was no statistically significant difference between treatments in FEV1 ( $\mathrm{p}=0.395$ ) (fig. 3). The only significant correlation between changes in sputum eosinophils and changes in clinical endpoints was seen with per cent change in FEV1 $(\mathrm{r}=-0.41, \mathrm{p}=0.012)$.

\section{Adverse experiences}

Montelukast was generally well tolerated in this study. There were few clinical adverse experiences and their frequency in the montelukast and placebo groups were similar. Three patients were discontinued due to clinical adverse experiences. One placebo patient was withdrawn due to worsening asthma. One montelukast patient was withdrawn due to sarcoidosis believed by the investigator to have been present at the prestudy visit; another montelukast patient was withdrawn because of abdominal pain. Laboratory adverse experiences were also infrequent and similar between montelukast and placebo. No patient was discontinued due to a laboratory adverse experience.

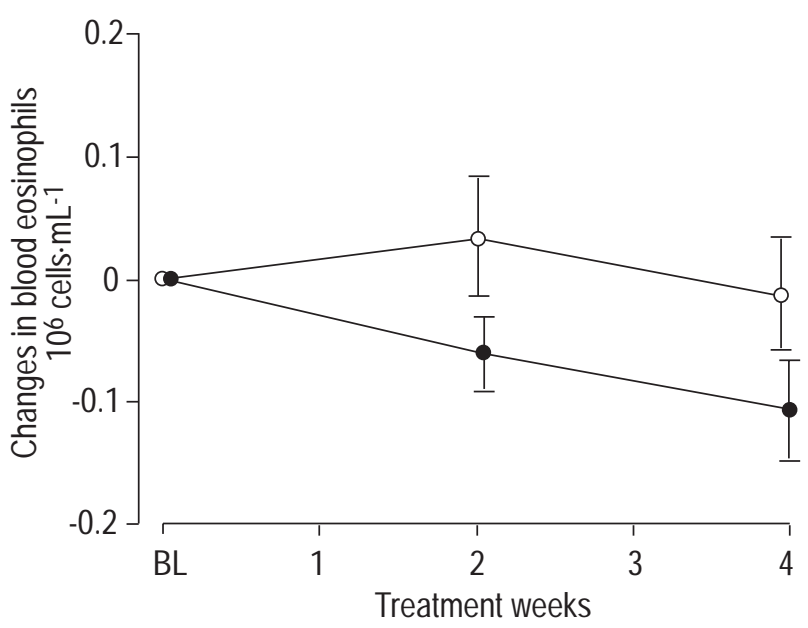

Fig. 2. - The effect of montelukast $(\bigcirc)$ and placebo $(\bigcirc)$ on peripheral blood eosinophils at baseline (BL) and 2 and 4 weeks after allocation. Vertical bars represent mean \pm SEM. Over the 4 -week period, montelukast caused a significant $(\mathrm{p}=0.009)$ reduction compared with placebo in peripheral blood eosinophils.

\section{Discussion}

In this randomized trial, daily treatment with montelukast for 4 weeks reduced sputum and blood eosinophils and improved clinical asthma control compared with placebo. A small effect on sputum eosinophils was seen after 1 week and this was significant after 4 weeks of therapy. These results raise the possibility that the decreases in sputum eosinophils might have contributed to the clinical improvement.

This is the first report of the effect of montelukast on airway eosinophilic inflammation in humans. The decrease in eosinophils was identified by the repeated examination of induced sputum, a method which is noninvasive and has been shown to be successful, reliable and responsive to change with treatment [28]. The effect of montelukast on blood eosinophils has also been demonstrated in previous studies $[16,17]$.

The results, not confounded by other asthma treatments, were obtained in patients with chronic asthma and with a relatively small sample size. Montelukast treatment, despite a lower baseline, decreased sputum eosinophils, while an increase was observed in the placebo group. The direction of the changes, despite baseline differences, provided strong evidence for a treatment effect by working against changes expected via regression to the mean [29]. In the absence of a treatment effect, the regression to the mean would cause changes in the opposite direction, reducing the treatment effect. Future studies might consider stratifying patients by baseline eosinophil percentages, to ensure they are similar in the treatment groups.

Standard, study-wide methodology to ensure sputum induction and processing consistency was employed; all technicians were trained centrally. The use of two independent and highly trained haematology technicians to read the cytospins minimized potential sources of bias. A validation of these same two slide readers had previously been shown to be highly repeatable and concordant [19].

An inhibition of eosinophil chemotaxis by montelukast may explain the results in this study. CysLTs have been shown to attract eosinophils, and LT antagonists could 

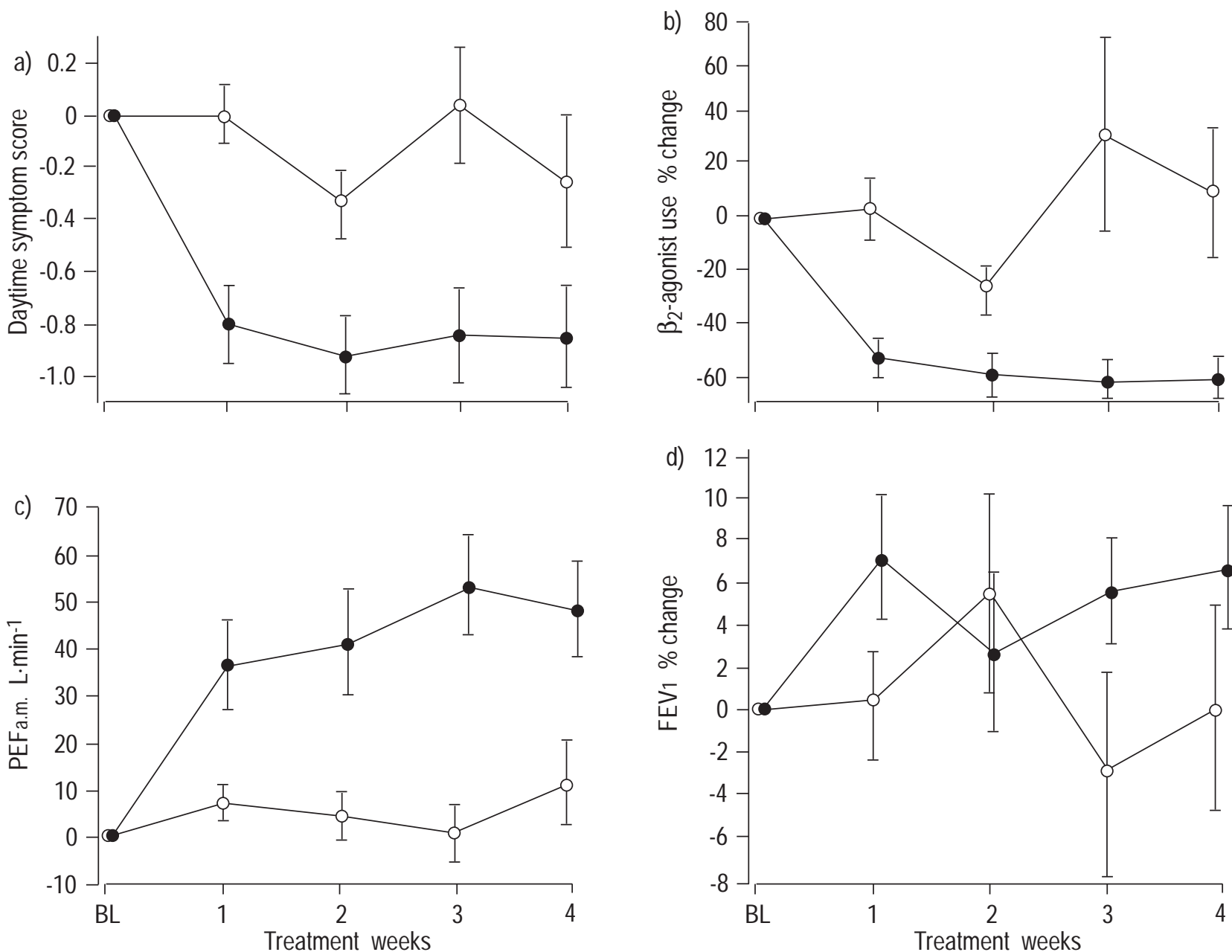

Fig. 3. - The effect of montelukast $(\bigcirc)$ and placebo $(\bigcirc)$ on: a) daytime symptoms; b) $\beta_{2}$-agonist use (puffs $\cdot$ day ${ }^{-1}$ ); c) morning peak expiratory flow (PEFa.m.); and d) forced expiratory volume in one second (FEV1) over the 4-week treatment period. Vertical bars represent mean \pm SEM change from baseline (BL). Treatment with montelukast caused significant reductions in daytime symptoms $(\mathrm{p}=0.002)$ and $\beta_{2}$-agonist use $(\mathrm{p}<0.001)$ and increases in PEFa.m. (p=0.001).

potentially block these effects. For example, SPADA et al. [7] showed $\mathrm{LTD}_{4}$ to be a potent and selective chemoattractant for human eosinophils at physiologically relevant concentrations. Using radiolabelled eosinophils in guinea-pig conjunctiva, CHAN et al. [9] showed administration of $\mathrm{LTD}_{4}$ induced a 2.5 -fold increase in conjunctival radioactivity (a measure of eosinophil chemotaxis) in vivo. Utilizing aerosolized $\mathrm{LTD}_{4}$, UNDERWOOD et al. [8] demonstrated inhaled LTs elevated BAL eosinophils in guineapig airways; increased eosinophil numbers were confirmed histologically in the bronchial epithelium and subepithelium. Finally, LAITINEN et al. [10] showed inhaled LTE increased eosinophils (but not mast cells, lymphocytes, plasma cells or macrophages) in the lamina propria of the airways of patients with asthma.

Corticosteroids and antileukotriene agents have been shown to affect sputum eosinophils in patients with asthma. In a 3-week placebo-controlled study, inhaled beclomethasone $(1,000 \mu \mathrm{g}$ daily) decreased sputum eosinophils by $73 \%$, (45\% decrease with placebo treatment, net difference $28 \%$ ) [30]. Similarly, inhaled beclomethasone $\left(1,000 \mu \mathrm{g} \cdot \mathrm{day}^{-1}\right)$ reduced sputum eosinophils in a 4-week study comparing beclomethasone with salmeterol [31], and treatment with budesonide (400 $\mu \mathrm{g} \cdot \mathrm{day}^{-1}$ for 7 days) attenuated the increase in eosinophils after antigen challenge [3]. In the present study, the $48 \%$ decrease in sputum eosinophils after montelukast treatment (compared with the 23\% increase after placebo) is similar in magnitude (net difference of $71 \%$ ) to the effects seen with corticosteroids in other studies; however, direct within-study comparisons are necessary to confirm this interpretation. An additional, interesting observation in the present trial is the large improvement observed in most clinical endpoints (PEF, $\beta_{2}$-agonist use, symptoms) which, on average, are greater than the effect seen in other montelukast trials [16, 17]. The explanation for this observation is unknown (and may be a chance variation), but may be due to the selection of patients with more substantial airway eosinophilic inflammation. However, the correlation between improvements in sputum eosinophils and clinical endpoints was generally modest; the relationship between changes in clinical endpoints and airways eosinophils is unknown and awaits further clinical trials.

This study was neither designed nor powered to prospectively determine the correlation between sputum markers and clinical outcomes. Therefore, the weak correlations between improvement in sputum eosinophils and clinical outcomes is likely to be an effect of the small range of 
airflow limitation, symptoms and $\beta_{2}$-agonist use observed in these mildly symptomatic asthmatic patients. However, it has been reported in prednisone-dependent asthmatics [32] that the improvement in clinical parameters after treatment of asthma with prednisone preceded the complete resolution of sputum inflammatory markers. Additionally, during a programmed reduction in prednisone dose, the inflammatory markers in sputum exacerbated before the clinical outcomes. The improvement of clinical parameters before the improvement of airway inflammation was also observed after treatment in nonprednisone-dependent asthmatics with a severe exacerbation of asthma [33]. These observations indicate that changes in clinical parameters may not be completely explained by changes in airway inflammation.

In summary, these results have shown that montelukast, a leukotriene receptor antagonist, reduced sputum and blood eosinophils, and improved clinical endpoints of asthma. The reduction in eosinophilic inflammation may contribute to the beneficial effects of montelukast in chronic asthma.
8. Underwood DC, Osborn RR, Newsholme SJ, Torphy TJ, Hay DWP. Persistent airway eosinophilia after leukotriene (LT) $\mathrm{D}_{4}$ administration in the guinea pig. $\mathrm{Am} \mathrm{J}$ Respir Crit Care Med 1996; 154: 850-857.

9. Chan CC, McKee K, Tagari P, Chee P, Ford-Hutchinson A. Eosinophil-eicosanoid interactions: inhibition of eosinophil chemotaxis in vivo by a $\mathrm{LTD}_{4}$-receptor antagonist. Clinical Allergy 1990; 15: 411-418.

10. Laitinen L, Laitinen A, Haahtela T, Spur B, Vilkka V, Lee $\mathrm{TH}$. Leukotriene $\mathrm{E}_{4}$ and granulocytic infiltration into asthmatic airways. Lancet 1993; 341: 989-990.

11. Diamant Z, Hilterman JT, van Rensen EL, et al. The effect of inhaled leukotriene $\mathrm{D}_{4}$ and methacholine on sputum cell differentials in asthma. Am J Respir Crit Care Med 1997; 155: 1247-1253.

12. Wenzel SE, Trudeau JB, Kaminsky DA, Cohn J, Martin RJ, Westcott JY. Effect of 5-lipoxygenase inhibition on bronchoconstriction and airway inflammation in nocturnal asthma. Am J Respir Crit Care Med 1995; 152: 897-905.

13. Kane GC, Pollice M, Kim CJ, et al. A controlled trial of the effect of the 5-lipoxygenase inhibitor, zileuton, on lung inflammation produced by segmental antigen challenge in human beings. J Allergy Clin Immunol 1996; 97 : 646-654.

14. Reiss TF, Sorkness CA, Stricker W, et al. Effects of montelukast (MK-0476), a potent cysteinyl leukotriene receptor antagonist, on bronchodilation in asthmatic patients treated with and without inhaled corticosteroids. Thorax 1997; 52: 45-48.

15. DeLepeleire I, Reiss TF, Rochette F, et al. Montelukast causes prolonged, potent leukotriene $\mathrm{D}_{4}$-receptor antagonism in the airways of patients with asthma. Clin Pharmacol Ther 1997; 61: 83-92.

16. Noonan MJ, Chervinsky P, Brandon M, et al., for the Montelukast Asthma Study Group. Montelukast, a potent leukotriene receptor antagonist, causes dose-related improvements in chronic asthma. Eur Respir J 1998; 11: $1232-1239$

17. Reiss TF, Chervinsky $\mathrm{P}$, Dockhorn RJ, Shingo S, Seidenberg B, Edwards TB, for the Montelukast Clinical Research Study Group. Montelukast, a once daily leukotriene receptor antagonist in the treatment of chronic asthma a multicenter, randomized, double-blind trial. Arch Intern Med 1998; 158: 1213-1220.

18. Leff JA, Busse WW, Pearlman D, et al. Treatment of mild asthma and exercise-induced bronchoconstriction with montelukast, a leukotriene receptor antagonist. $N$ Engl $J$ Med 1998; 339: 147-152.

19. Pizzichini E, Pizzichini MMM, Efthimiadis A, et al. Indices of airway inflammation in induced sputum: reproducibility and validity of cell and fluid-phase measurements. Am J Respir Crit Care Med 1996; 154: 308-317.

20. Claman DM, Boushev HA, Liu J, Wong H, Fahy JV. Analysis of induced sputum to examine the effects of prednisone on airway inflammation in asthmatic patients. J Allergy Clin Immunol 1994; 94: 861-869.

21. Gibson PG, Hargreave FE, Girgis-Gabardo A, Morris M, Denburg JA, Dolovich J. Chronic cough with eosinophilic bronchitis: examination for variable airflow obstruction and response to corticosteroid. Clin Exp Allergy 1995; 25: 127-132.

22. Pin I, Gibson PG, Kolendowicz R, et al. Use of induced sputum cell counts to investigate airway inflammation in asthma. Thorax 1992; 47: 25-29.

23. Pizzichini E, Pizzichini MM, Kidney JC, et al. Induced sputum, bronchoalveolar lavage and blood from mild 
asthmatics: inflammatory cells, lymphocyte subsets and soluble markers compared. Eur Respir J 1998; 111: 828834.

24. Santanello NC, Barber BL, Reiss TF, Friedman BS, Juniper EF, Zhang J. Measurement characteristics of two asthma symptom diary scales for use in clinical trials. Eur Respir J 1997; 10: 646-651.

25. Crapo RO, Hankinson JL, Irvin C. Standardization of spirometry. Am J Respir Crit Care Med 1995; 1562: 1102-1136.

26. Lin LI. A concordance correlation coefficient to evaluate reproducibility. Biometrics 1989; 45: 255-268.

27. Pizzichini E, Pizzichini MMM, Dolovich J, Hargreave FE. Measuring airway inflammation in asthma: eosinophils and ECP in induced sputum compared with peripheral blood. J Allergy Clin Immunol 1997; 99: 539-544.

28. Hargreave FE, Pizzichini MMM, Pizzichini E. Assessment of airway inflammation. In: Barnes PJ, Grunstein MM, Leff J, Wooilcock A, eds. Asthma. Vol 2. New York, Raven Press, 1997; pp. 1433-1450.
29. Anderson B. Regression towards the mean. In: Anderson B, ed. Methodological Errors in Medical Research. Cambridge, MA, Blackwell Scientific Publications, 1990; pp. 98-109.

30. Di Franco A, Bacci E, Cianchetti S, et al. Effect of inhaled steroids on sputum eosinophil count in naive asthmatic patients. Am J Respir Crit Care Med 1996; 153 : A293.

31. Turner MO, Johnston PR, Pizzichini E, Pizzichini MM, Hussack PA, Hargreave FE. Anti-inflammatory effects of salmeterol compared with beclomethasone in eosinophilic mild exacerbations of asthma: a randomized, placebo controlled trial. Can Respir J 1998: 5: 261-268.

32. Pizzichini MM, Pizzichini E, Clelland L, et al. Prednisone dependent asthma: inflammatory indices in induced sputum. Eur Respir J 1999; 13: 15-21.

33. Pizzichini MMM, Pizzichini E, Clelland L, et al. Sputum in severe exacerbations of asthma: kinetics of inflammatory indices after prednisone treatment. Am J Respir Crit Care Med 1997; 155: 1501-1508. 